\title{
Ultrasonically assisted synthesis of lead oxide nanoflowers using ball milling
}

\author{
Uzma K. H. Bangi ${ }^{1,2}$ - Hyung-Ho Park ${ }^{2}$ Wooje Han ${ }^{2}$ Vipul M. Prakshale ${ }^{1}$. \\ Lalasaheb P. Deshmukh ${ }^{1}$
}

Received: 4 November 2016/ Accepted: 26 April 2017/Published online: 2 May 2017

(c) The Author(s) 2017. This article is an open access publication

\begin{abstract}
The experimental results on the ultrasonically assisted synthesis of lead oxide nanoflowers using ball milling have been reported in the present work. Lead oxide nanoflowers were prepared employing mixed ligands by subjecting the formed precipitate to ultrasonication and grinding/ball milling. The effect of ball milling as well as fine grinding in agate mortar on the microstructure and surface morphology of the lead oxide was studied. The characteristics of synthesized $\mathrm{PbO}$ were studied using X-ray diffraction, X-ray photoelectron spectroscopy, Fourier transform infrared spectroscopy and field emission scanning electron microscopy techniques. XRD results demonstrated the tetragonal phase of $\mathrm{PbO}$ with crystallite size of around $25 \mathrm{~nm}$ and strain of $3.6 \times 10^{-3}$ calculated from Williamson-Hall plot. FESEM images manifested the formation of nanodiscs and nanoflowers with a diameter of around $300 \mathrm{~nm}$ and thickness of $50 \mathrm{~nm}$. XPS spectra revealed the formation of $\mathrm{PbO}$ with photoelectron peak of $\mathrm{Pb} 4 \mathrm{f}$ and $\mathrm{O} 1 \mathrm{~s}$ lied at 137.68 and $529.96 \mathrm{eV}$. Moreover, FTIR spectrum exhibited $\mathrm{Pb}-\mathrm{O}$ bond peak in the range of $400-530 \mathrm{~cm}^{-1}$.
\end{abstract}

Keywords Precipitation · Ultrasonication - Ball milling · $\mathrm{PbO}$ nanoflowers

Uzma K. H. Bangi

uzma.phys@gmail.com

1 School of Physical Sciences, Solapur University, SolapurPune National Highway, Kegaon, Solapur, Maharashtra 413 255, India

2 Department of Materials Science and Engineering, Yonsei University, Seodaemun-gu, Seoul 120-749, Republic of Korea

\section{Introduction}

The growing demands of energy and the degradation of non-renewable resources have led to the conversion and storage of solar energy through photovoltaic method. Therefore, recently, the researchers have been seeking alternative materials and methods to improve the efficiency of solar cells. Lead oxides, existing in four basic types, namely, $\mathrm{PbO}, \mathrm{PbO}_{2}, \mathrm{~Pb}_{2} \mathrm{O}_{3}$ and $\mathrm{Pb}_{3} \mathrm{O}_{4}$, have wide applications including semiconductors, transparent conductors, batteries, electro-catalysts, gas sensors, solar energy conversion materials, and other electronic or electronic related materials. Amongst these, $\mathrm{PbO}$ (lead monoxide) was utilized as a photoactive layer in Schottky type photovoltaic devices $[1,2]$ and a surface modification layer in inverted polymer solar cells [3]. $\mathrm{PbO}$ exists in two polymorphic forms as a tetragonal phase ( $\alpha-\mathrm{PbO}$ or litharge), and an orthorhombic phase ( $\beta-\mathrm{PbO}$ or massicot). Though both phases have very low electrical conductivity $\left(\approx 10^{-12}\right.$ mho $\mathrm{cm}^{-1}$ ), they exhibit interesting semiconducting and photoconducting properties. $\alpha-\mathrm{PbO}$ and $\beta-\mathrm{PbO}$ are photoactive semiconductors with band gaps of 1.92 and $2.7 \mathrm{eV}$, respectively. $\alpha-\mathrm{PbO}$ has potential application in photovoltaic [4] while $\beta-\mathrm{PbO}$ was used as a surface modification layer for lowering work functions [3]. In recent years, $\mathrm{PbO}$ nanoparticles and nanostructures have been prepared via different chemical techniques, such as precipitation, hydrothermal, sonochemical, etc. Till date, to synthesize $\mathrm{PbO}$ nanostructures viz. nanoparticles [5], nanorods [6], nanosheets [7, 8] as well as nanowires, hexagonal nanoplates, and microspheres [9, 10] above mentioned chemical techniques have been used. But, there are rare reports on the synthesis of $\mathrm{PbO}$ nanodiscs/nanoflowers using simple and cost-effective precipitation method. It is well known that the high surface 
area of nanostructures like nanorods, nanosheets, nanowires and nanodiscs, etc., of any material has profound effect on their applications. The size and shape of these structures can be controlled using capping ligand as reported elsewhere $[11,12]$. It was reported that nanocomplexing with polymer can be used to combine the desirable properties of nanoparticles and polymer to be used in the Organic Thin Film Transistor (OTFT) [13]. In a similar way, the high surface area of semiconducting $\mathrm{PbO}$ nanostructures and electrical conductivity of polymers can be combined to be applied in the photovoltaic device. Besides the effect of capping ligand, it was also observed that the shape and size as well as surface area of the nanostructure can be influenced by the ultrasonic waves [14]. There are many reports on the synthesis of $\mathrm{PbO}$ and $\mathrm{PbO}_{2}$ nanostructures using sonochemical (ultrasonication) methods [14, 15]. Ultrasonication can also cause the aggregation of the precipitated primary particles leading to 1D, 2D or 3D nanostructures. Further, the ball milling and fine grinding of the dried powder help to reduce the particle size and their aggregation. Taking all these into account, attempts have been made to synthesize $\mathrm{PbO}$ nanodiscs/nanoflowers using simple method of precipitation employing ultrasonication and the effects of ball milling as well as fine grinding in agate mortar on the structure and morphology of $\mathrm{PbO}$ have been studied.

\section{Experimental}

The successful synthesis of $\mathrm{PbO}$ nanoflowers via cost-effective precipitation method employing ultrasonication has been carried out. The chemicals used for the synthesis of $\mathrm{PbO}$ nanodiscs/nanoflowers were as follows: lead nitrate $\left[\mathrm{Pb}\left(\mathrm{NO}_{3}\right)_{2}\right.$, Sigma Aldrich] as a starting material, oxalic acid $\left(\mathrm{C}_{2} \mathrm{H}_{2} \mathrm{O}_{4}\right.$, Sigma Aldrich) as a precipitant, and polyvinyl pyrrolidone (PVP, mol wt 40,000 g, Sigma Aldrich) and cetyl trimethyl ammonium bromide CTAB (CTAB, mol wt $364.46 \mathrm{~g}$, Sigma Aldrich) as a capping ligands. Ethanol (EtOH) and D.I. water were used to remove impurities from the precipitate, and hexane was used as a surfactant during ball milling.

The schematic flowchart for the synthesis of $\mathrm{PbO}$ nanodiscs/nanoflowers is presented in Fig. 1. The preparation of $\mathrm{PbO}$ was carried out by successive addition of PVP and CTAB as reported elsewhere [5]. To study the effects of fine grinding and ball milling on morphology of $\mathrm{PbO}$, three samples were prepared as PN1 (without grinding or milling), PN2 (fine ground for $30 \mathrm{~min}$.), and PN3 (ball milled for $24 \mathrm{~h}$ ). In a typical procedure, the aqueous lead nitrate $(0.01 \mathrm{M})$ was

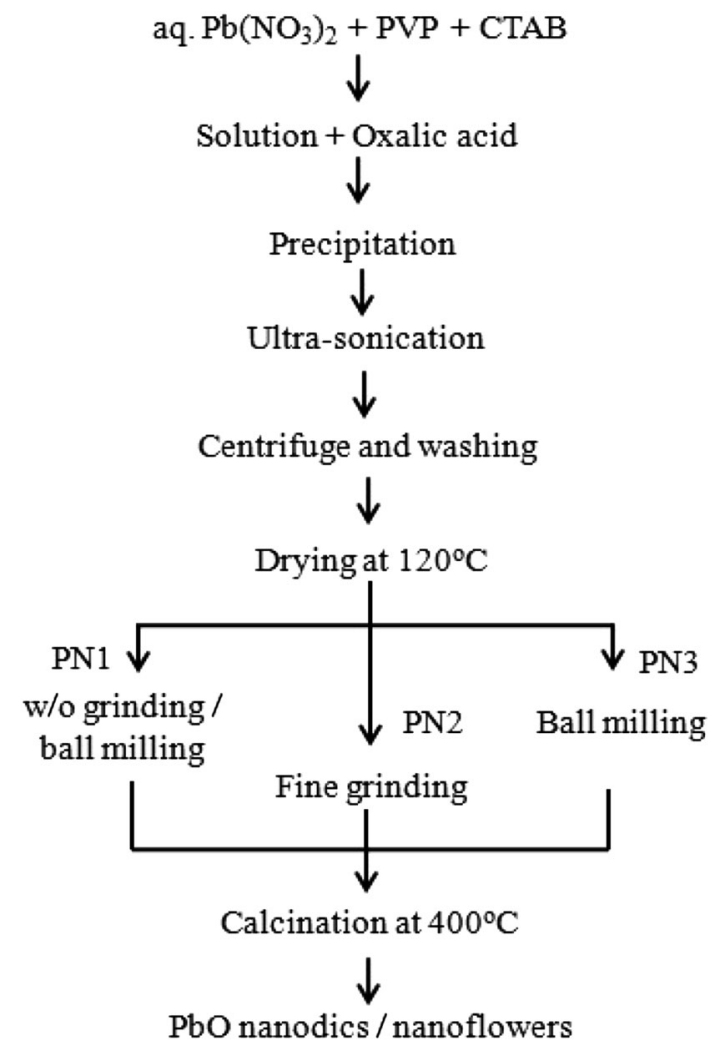

Fig. 1 Experimental flowchart for the synthesis of $\mathrm{PbO}$ nanodisc/nanoflowers

mixed with PVP $(0.005 \mathrm{M})$ and CTAB $(0.05 \mathrm{M})$ under stirring for $60 \mathrm{~min}$ followed by addition of oxalic acid $(0.01 \mathrm{M})$ under stirring of $30 \mathrm{~min}$. During the synthesis the volume ratio of $\mathrm{Pb}\left(\mathrm{NO}_{3}\right)_{2}$ :oxalic acid:(PVP/CTAB) was kept at 1:1:0.05. This gives a white precipitate which was subjected to ultrasonication at $70{ }^{\circ} \mathrm{C}$ for the period of $3 \mathrm{~h}$, centrifugation at 10,000 rpm for $10 \mathrm{~min}$ and washing with DI $\mathrm{H}_{2} \mathrm{O}$ and $\mathrm{EtOH}$, respectively. The as processed precipitates were dried at $120{ }^{\circ} \mathrm{C}$ over $24 \mathrm{~h}$, fine grand for $30 \mathrm{~min}$ and ball milled (as reported in Ref. [5]) before calcination. Afterwards, each sample was calcined in $\mathrm{O}_{2}$ atmosphere in a tube furnace at $400{ }^{\circ} \mathrm{C}$ for $1 \mathrm{~h}$ with heating rate of $15^{\circ} \mathrm{C} \mathrm{min}{ }^{-1}$. The samples were used for characterization after furnace was cooled to room temperature (RT). Powder X-ray diffraction (XRD, RIGAKU Ultima IV diffractometer, Japan) patterns were acquired on a diffractometer using $\mathrm{Cu} \mathrm{K} \alpha(\lambda=1.541 \AA)$ radiation operating at $40 \mathrm{kV}$ and $30 \mathrm{~mA}$. Diffraction was carried out in range $(2 \theta)$ from $20^{\circ}$ to $80^{\circ}$ at a scanning speed of $4^{\circ} \mathrm{min}^{-1}$. The crystallite size $(D)$ and strain $(\varepsilon)$ of $\mathrm{PbO}$ samples were calculated using the Williamson-Hall (W-H) plot by plotting the graph of $\beta \cos \theta$ vs $4 \sin \theta$. The $\mathrm{W}-\mathrm{H}$ relation is as below [16]: 


$$
\beta \cos \theta=(0.89 \lambda / D)+4 \varepsilon \sin \theta
$$

where, $\lambda$ is the wavelength of $\mathrm{Cu} \mathrm{K \alpha}$ radiation, $\beta$ is the integral width of peak and $\theta$ is the diffraction angle. The crystallite size and strain induced were extracted from the $y$-intercept and slope of W-H plot using Eq. (1), respectively.

The dislocation densities in the synthesized $\mathrm{PbO}$ samples were estimated using the following formula (Eq. 2).

$\delta=1 / D^{2}$

where $D$ is the crystallite size obtained from $\mathrm{W}-\mathrm{H}$ plot.

The effect of fine grinding and ball milling on morphology of $\mathrm{PbO}$ samples was studied using field emission scanning electron microscopy (FESEM, JEOL JSM-600F, Japan) with an acceleration voltage of $15 \mathrm{kV}$. X-ray photoelectron spectroscopy (XPS) at the 4D beamline of the Pohang Accelerator Laboratory (South Korea) was used to analyze the chemical bonding state of as synthesized $\mathrm{PbO}$ using incident photon energy of $650 \mathrm{eV}$. The evolution of chemical bonds in $\mathrm{PbO}$ samples was monitored using Fourier transform infrared spectroscopy (FTIR, PerkinElmer spectrometer, UK) ranging from 3500 to $350 \mathrm{~cm}^{-1}$.

\section{Results and discussion}

Ultrasonic synthesis results in chemical or physical changes in the materials properties. It involves a phenomenon of cavitation leading to the formation, growth and collapse of the bubbles in liquid [17]. This generates local hot spots having the temperature of thousands of ${ }^{\circ} \mathrm{K}$, and pressure of hundreds of atmosphere along with a lifetime of few microseconds. The physiochemical effects of cavitation strongly depend on the vapor pressure, viscosity and temperature of the liquid as well as ultrasonic intensity. Ultrasonic radiation provides the thermal energy to decompose the complex precipitate to fine primary particles and then prevent their aggregation. For the synthesis of $\mathrm{PbO}$, the formed precipitate was subjected to ultrasonication at $70{ }^{\circ} \mathrm{C}$ for $3 \mathrm{~h}$ and the effects of ball milling and fine grinding on the microstructure and morphology of as synthesized $\mathrm{PbO}$ have been studied as follows.

Figure 2 shows XRD diffractograms of PN1, PN2 and PN3 samples synthesized via precipitation method followed by ultrasonication. All three samples exhibit tetragonal crystal structure of $\mathrm{PbO}$ matching with the JCPDS data card number PDF\#85-1287. The corresponding diffraction peaks are indexed as (1 010$),\left(\begin{array}{lll}1 & 1 & 0\end{array}\right),\left(\begin{array}{lll}2 & 0 & 0\end{array}\right)$,

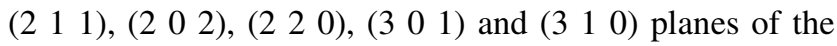
tetragonal $\mathrm{PbO}$ with a sharper and stronger peak of (101)

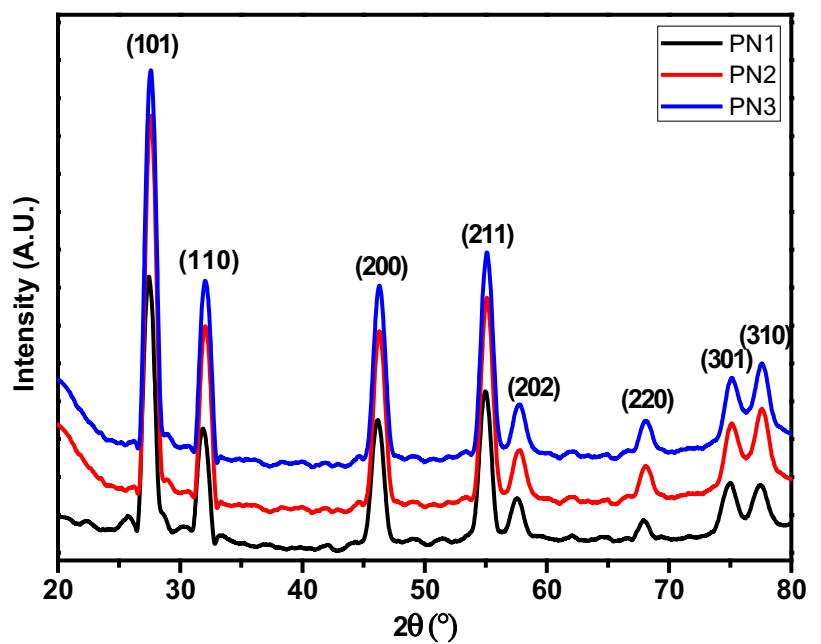

Fig. 2 XRD diffractograms of PN1, PN2 and PN3 samples

indicating phase orientation along $<101>$. Figure 3 manifests the W-H plots for PN1, PN2 and PN3 samples. The crystallite size of PN1, PN2 and PN3 samples estimated by the W-H plot (Fig. 3) and Eq. (1) are nearly 80.67, 152.38 and $24.93 \mathrm{~nm}$, respectively. Also the strain and dislocation density of PN1, PN2 and PN3 samples derived using W-H plot and Eqs. (1) and (2) are tabulated as in Table 1. The lower crystallite size of the PN3 sample is because the ball milling enormously helps to break the precipitated powder to nano size powder through the impact of centrifugal forces. Ball milling provides sufficient energy for reduction of particles size of the final product. Therefore, PN3 samples have lower crystallite size (compared to PN1) with the strain value of $3.6 \times 10^{-3}$ and dislocation density of $1.61 \times 10^{15} \mathrm{~m}^{-2}$. The higher crystallite size of PN2 samples $(152.38 \mathrm{~nm})$ clearly manifests that grinding in agate mortar has no significant effect on reducing the size of precipitated powder. As seen from Eq. (2), the dislocation density is inversely proportional to square of crystallite size, therefore, $\delta$ is larger for PN3 sample as compared to PN1 and PN2 (Table 1). Hence, Table 1 exhibited that PN3 sample i.e., $\mathrm{PbO}$ nanoflowers consists of very fine crystallites.

The FESEM micrographs of PN1, PN2 and PN3 samples are shown in Fig. 4. From Fig. 4, it seems that PN1 and PN2 samples consist of nanodiscs while PN3 sample consists of nanoflowers. The diameter and thickness of nanodiscs in sample PN2 were measured to be around 300 and $50 \mathrm{~nm}$, respectively, which may be nearly the same in case of PN1 and PN3 samples. $\mathrm{PbO}$ nanodisc formation is because of the ultrasonication which facilitates the reduction in particle size preventing the agglomeration and these primary particles aggregate to form nanodiscs during calcination at high temperature 

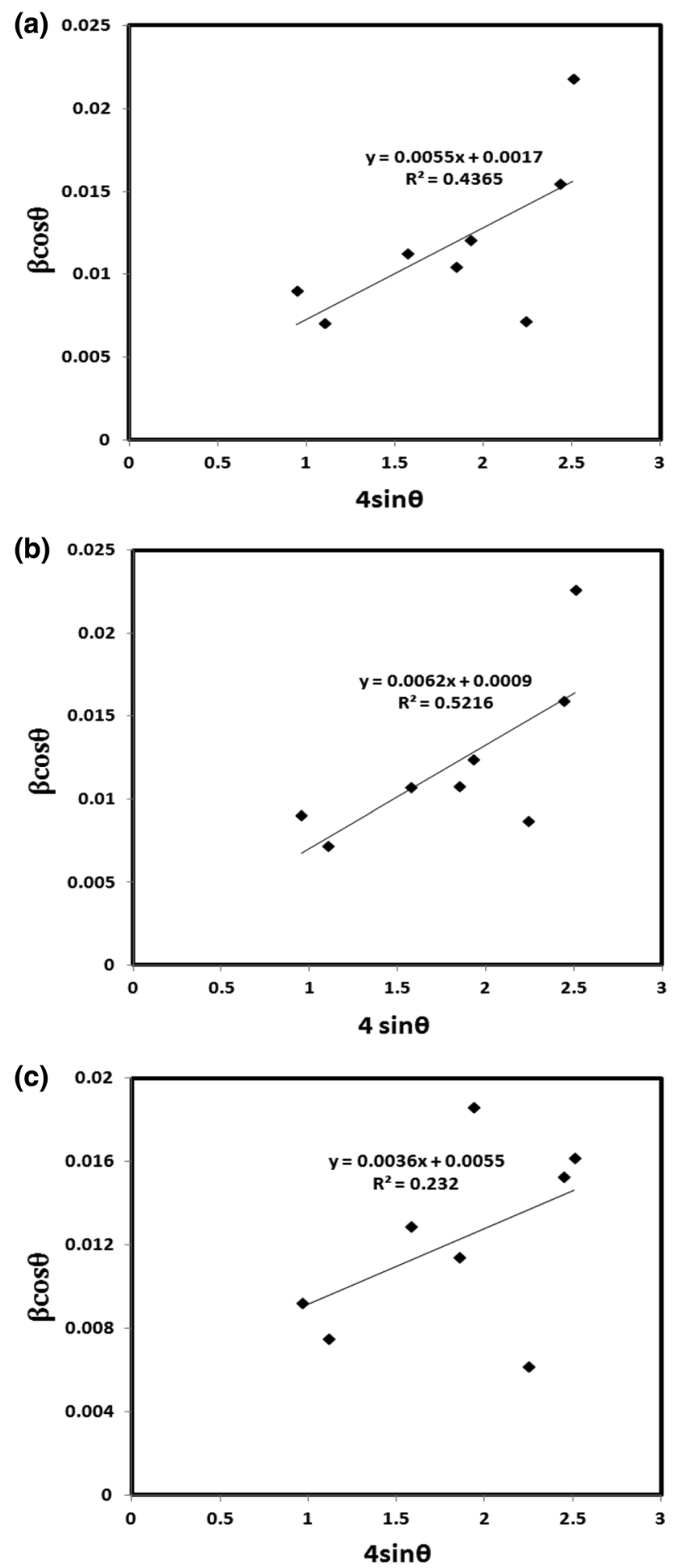

Fig. 3 W-H plots for a PN1, b PN2 and c PN3 samples

$\left(400{ }^{\circ} \mathrm{C}\right)$. The reason behind this is that a higher surface energy possessed by the nanoparticles makes them aggregate once it goes into a solid-state condition [18].
Table 1 Crystallite size, strain and dislocation density of PN1, PN2 and PN3 samples calculated using $\mathrm{W}-\mathrm{H}$ plot

\begin{tabular}{|c|c|c|c|}
\hline Sample identity & PN1 & PN2 & PN3 \\
\hline $\begin{array}{l}\text { Crystallite size }(D) \\
\text { nm }\end{array}$ & 80.67 & 152.38 & 24.93 \\
\hline Strain $(\varepsilon)$ & $5.5 \times 10^{-3}$ & $6.2 \times 10^{-3}$ & $3.6 \times 10^{-3}$ \\
\hline $\begin{array}{l}\text { Dislocation density }(\delta) \\
\mathrm{m}^{-2}\end{array}$ & $1.54 \times 10^{14}$ & $4.31 \times 10^{13}$ & $1.61 \times 10^{15}$ \\
\hline
\end{tabular}

Due to the centrifugal forces created by the rotation of ball milling system, the powder mixture is fractured and cold welded under the impact of high energy producing nanoflowers in case of sample PN3. The obtained nanopowders exist in random structure in an aggregated form of nanodisc or nanoflowers. The formation of nanodiscs or nanoflowers in $\mathrm{PbO}$ samples can be well understood by the pictorial representation as shown in Fig. 5. At first, the nucleation and growth lead to the formation of primary $\mathrm{PbO}$ particles, the size and shape of which mainly depend on their rate of formation [19]. After nucleation and growth, the particle size can change by aging processes of coarsening and aggregation. According to the Gibbs-Thomson equation for coarsening, the solubility of smaller particles is larger than that of larger particles due to capillary effect [19]. It means that rate of coarsening of small particles is faster. At last, the aggregation of coarsen particles occurs in a random fashion. The rate of coarsening of primary particles in case of PN1 and PN2 samples is smaller than PN3 sample due to ball milling. Therefore, the primary particles of sample PN3 which are significantly smaller than PN1 and PN2 aggregate to form the $\mathrm{PbO}$ nanoflower.

Figure 6 shows typical core-level XPS spectra of lead, oxygen, and carbon for PN3 sample. As shown in Fig. 6, the photoelectron peak of $\mathrm{Pb} 4 \mathrm{f}$ and $\mathrm{O} 1 \mathrm{~s}$ lying at 137.68 and $529.96 \mathrm{eV}$, respectively, are assigned to lattice lead and oxygen in a $\mathrm{PbO}$ crystal. The $4 \mathrm{f}$ spectrum of $\mathrm{PbO}$ comprises a simple spin-orbit doublet of 4f5/2 (at $137.68 \mathrm{eV})$ and $4 \mathrm{f} 7 / 2(142.48 \mathrm{eV})$ with a spin-orbit splitting of $4.8 \mathrm{eV}$ [20]. Further, the photoelectron peak of $\mathrm{C}$ $1 \mathrm{~s}$ lying at $285.01 \mathrm{eV}$ is assigned to carbon from PVP and CTAB capped around the PbO. FTIR spectrum of the PN3 sample is shown in Fig. 7. As seen from Fig. 7, the peaks in $400-530 \mathrm{~cm}^{-1}$ are related to the $\mathrm{Pb}-\mathrm{O}$ bond. Further, the peaks at 1046, 1330 and $2840-2950 \mathrm{~cm}^{-1}$ correspond to the bonds of $\mathrm{C}-\mathrm{N}, \mathrm{C}=\mathrm{O}$ and $\mathrm{C}-\mathrm{H}$ of $\mathrm{PVP}$ and $\mathrm{CTAB}$, indicating their capping on $\mathrm{PbO}$. The peak at 844 is related to the $\mathrm{C}-\mathrm{H}$ of the aromatic ring in PVP [5]. 


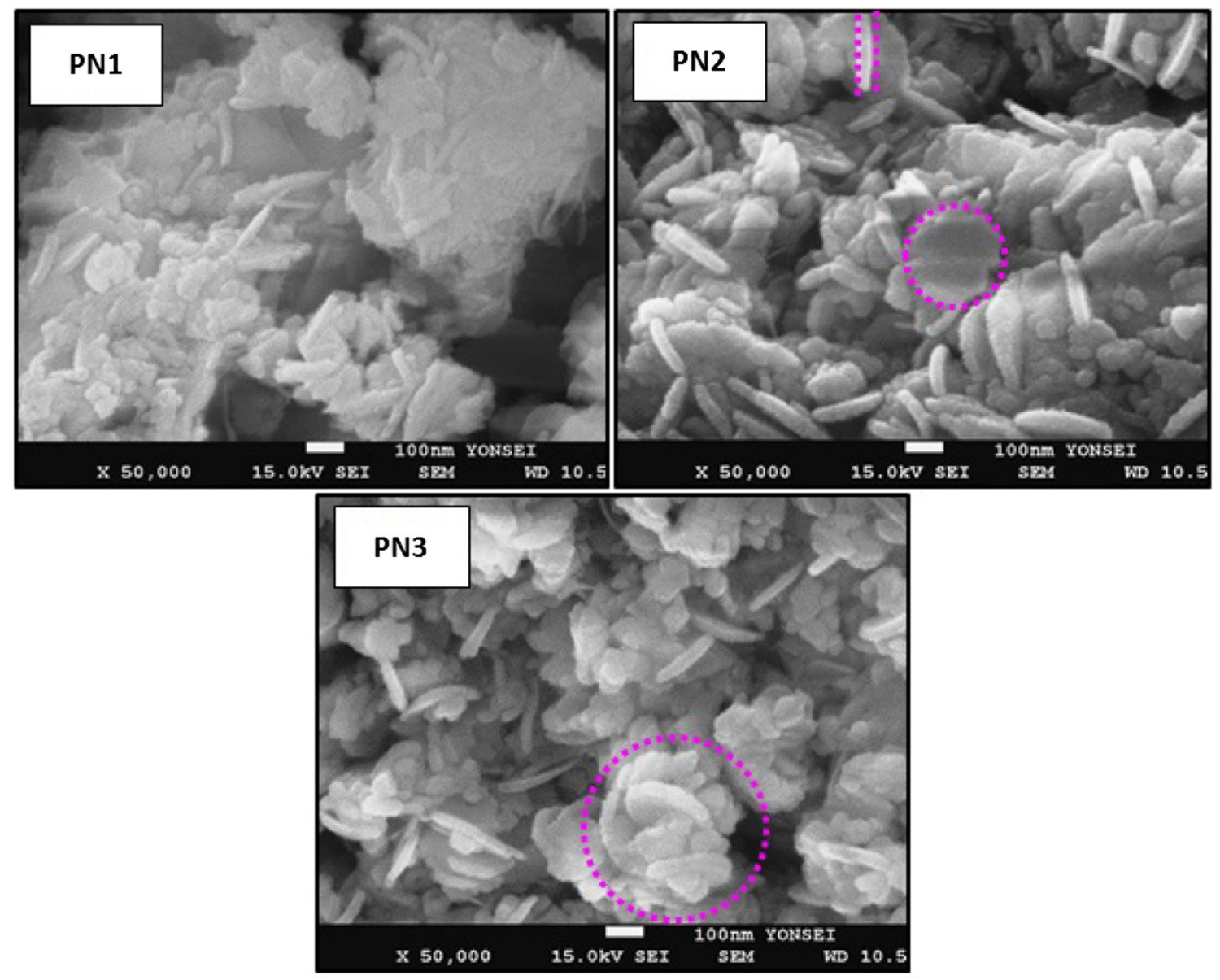

Fig. 4 FESEM images of PN1, PN2 and PN3 samples

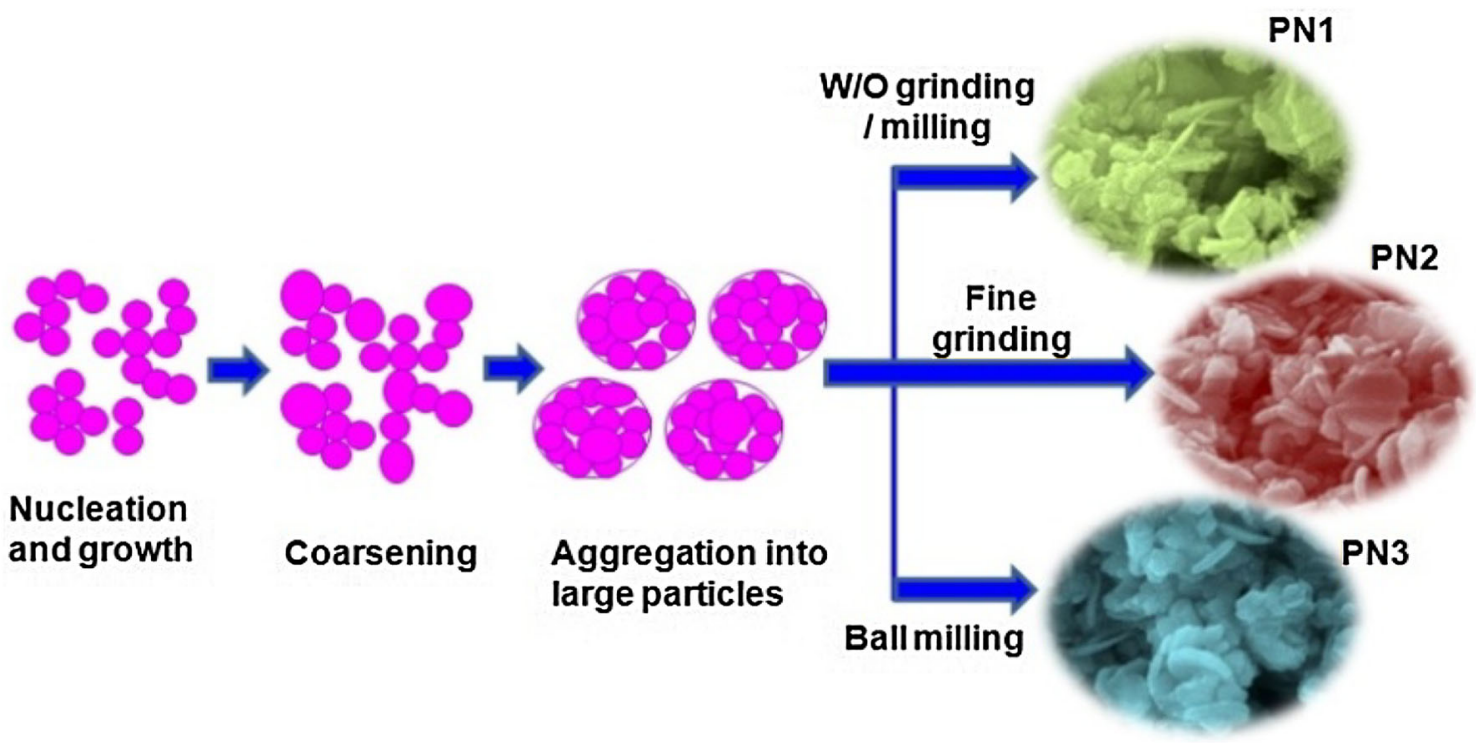

Fig. 5 Pictorial representation for the formation of $\mathrm{PbO}$ nanodiscs/nanoflowers 

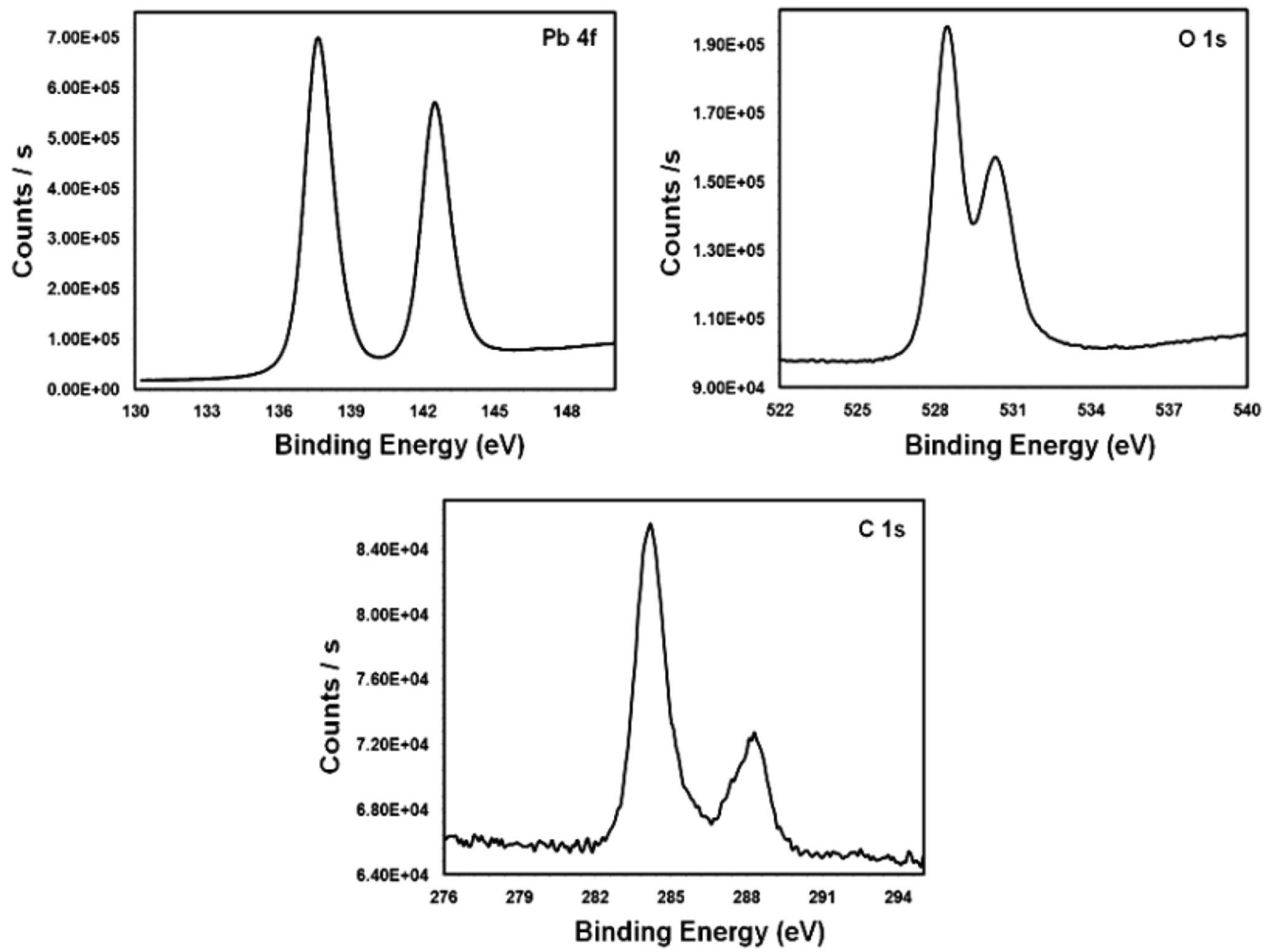

Fig. 6 Core-level XPS spectra of PN3 sample

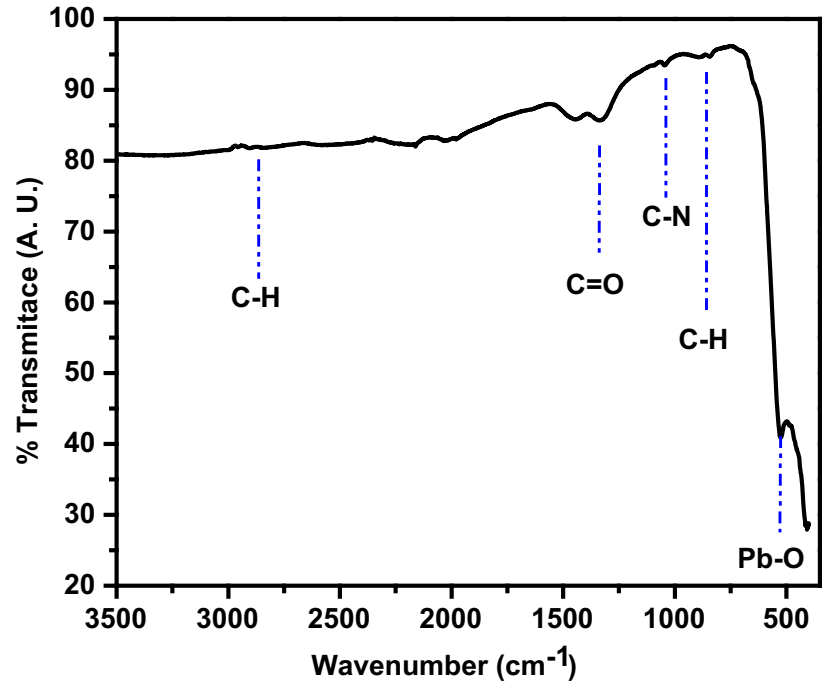

Fig. 7 FTIR spectrum of PN3 sample

\section{Conclusions}

The successful synthesis of ultrasonically assisted $\mathrm{PbO}$ nanoflowers using ball milling has been carried out. Ultrasonication and ball milling enormously helps to reduce the particle size. XRD study revealed the tetragonal crystal structure of $\mathrm{PbO}$ nanoflowers with average crystallite size of nearly $25 \mathrm{~nm}$. Moreover, the XPS and FTIR studies revealed the $\mathrm{PbO}$ formation.

Acknowledgements This study was supported by a Grant (\#10041220) from the Fundamental R\&D Program for Core Technology of Materials, funded by the Ministry of Knowledge Economy, Republic of Korea. One of the authors, Uzma K. H. Bangi, is very grateful to the Department of Science and Technology-Science \& Engineering Research Board (DST-SERB), New Delhi, India, for Young Scientist Fellowship under fast-track scheme through a major research project on 'aerogels' (No. SB/FTP/PS-030/2014).

Open Access This article is distributed under the terms of the Creative Commons Attribution 4.0 International License (http://crea tivecommons.org/licenses/by/4.0/), which permits unrestricted use, distribution, and reproduction in any medium, provided you give 
appropriate credit to the original author(s) and the source, provide a link to the Creative Commons license, and indicate if changes were made.

\section{References}

1. Cattley, C.A., Stavrinadis, A., Beal, R., Moghal, J., Cook, A.G., Grant, P.S., Smith, J.M., Assender, H., Watt, A.A.R.: Colloidal synthesis of lead oxide nanocrystals for photovoltaics. Chem. Commun. 46(16), 2802-2804 (2010)

2. Droessler, L.M., Assender, H.E., Watt, A.A.R.: Thermally deposited lead oxides for thin film photovoltaics. Mater. Lett. 71, 51-53 (2012)

3. Zhang, H., Ouyang, J.: High-performance inverted polymer solar cells with lead monoxide-modified indium tin oxides as the cathode. Organ Electron 12(11), 1864-1871 (2011)

4. Veluchamy, P., Minoura, H.: Simple electrochemical method for the preparation of a highly oriented and highly photoactive $\mathrm{PbO}$ film. Appl. Phys. Lett. 65(19), 2431-2433 (1994)

5. Bangi, U.K.H., Han, W., Yoo, B., Park, H.H.: Effects of successive additions of two capping ligands on the structural properties of PbO nanoparticles. J. Nanopart. Res. 15, 2070-2077 (2013)

6. Jia, B., Gao, L.: Synthesis and characterization of single crystalline $\mathrm{PbO}$ nanorods via a facile hydrothermal method. Mater. Chem. Phys. 100, 351-354 (2006)

7. Shakya, S., Prakash, G.V.: Formation of $\mathrm{PbO}$ hexagonal nanosheets and their conversion into luminescent inorganic-organic perovskite nanosheets: growth and mechanism. RSC Adv. 5, 27946-27952 (2015)

8. Zeng, S., Liang, Y., Lu, H., Wang, L., Dinh, X.Q., Yu, X., Ho, H.P., Hu, X., Yong, K.T.: Synthesis of symmetrical hexagonalshape $\mathrm{PbO}$ nanosheets using gold nanoparticles. Mater. Lett. 67, 74-77 (2012)

9. Wang, Q., Sun, X., Luo, S., Sun, L., Wu, X., Cao, M., Hu, C.: Controllable synthesis of $\mathrm{PbO}$ nano/microstructures using a porous alumina template. Cryst. Growth Des. 7(12), 2665-2669 (2007)
10. Jiang, X., Wang, Y., Herricks, T., Xia, Y.: Ethylene glycol-mediated synthesis of metal oxide nanowires. J. Mater. Chem. 14, 695-703 (2004)

11. Bangi, U.K.H., Deshmukh, L.P., Park, H.H., Maldar, N.N.: Costeffective synthesis of ultrafine $\mathrm{BaTiO}_{3}$ nanoparticles: some structural and morphological observation. In: Proceedings of the 2015 2nd International Symposium on Physics and Technology of Sensor (2015) (978-1-4673-8018-8/15/\$31.00 @ 2015 IEEE)

12. Bangi, U.K.H., Prakshale, V.M., Han, W., Park, H.H., Maldar, N.N., Deshmukh, L.P.: Microstructural characteristics of $\mathrm{SrTiO}_{3}$ nanoparticles: the role of capping ligand concentration. Micro Nano Lett. (2016). doi:10.1049/mnl.2015.0531

13. Han, W., Lee, H.S., Bangi, U.K.H., Yoo, B., Park, H.H.: Dielectric properties of poly(4-vinylphenol) with embedded $\mathrm{PbO}$ nanoparticles. Poly. Adv. Tech. (2015). doi:10.1002/pat.3627

14. Ghasemi, S., Mousavi, M.F., Shamsipur, M., Karami, H.: Sonochemical-assisted synthesis of nano-structured lead dioxide. Ultrason. Sonochem. 15, 448-455 (2008)

15. Karami, H., Karimi, M.A., Haghdar, S., Sadeghi, A., Rasool, M.G., Saeed, M.H.: Synthesis of lead oxide nanoparticles by sonochemical method and its application as cathode and anode of lead-acid batteries. Mater. Chem. Phys. 108, 337-344 (2008)

16. Mote1, V.D., Purushotham, Y., Dole1, B.N.: Williamson-Hall analysis in estimation of lattice strain in nanometer-sized $\mathrm{ZnO}$ particles. J. Theor. Appl. Phys. 6, 6-13 (2012)

17. Santos, H.M., Lodeiro, C., Capello-Martinez J.L.: The power of ultrasound. In: Capello-Martinez J.L. (eds.) Ultrasound in Chemistry: Analytical Applications, pp. 1-15. Wiley, Weinheim (2009)

18. Lee, J.: Drug nano- and microparticles processed into solid dosage forms: physical properties. J. Pharm. Sci. 92, 2057-2068 (2003)

19. Oskam, G.: Metal oxide nanoparticles, synthesis, characterization and application. J. Sol Gel Sci. Tech. 37, 161-164 (2007)

20. Payne, D.J., Egdell, R.G., Law, D.S.L., Glans, P.-A., Learmonth, T., Smith, K.E., Guo, J., Walsh, A., Watson, G.W.: Experimental and theoretical study of the electronic structures of $\mathrm{a}-\mathrm{PbO}$ and b- $\mathrm{PbO}_{2}$. J. Mater. Chem. 17, 267-277 (2007) 